\title{
Políticas e normativas aplicadas às creches municipais do Rio de Janeiro
}

\author{
Policies and standards applied to municipal day care centers \\ in Rio de Janeiro
}

Rafaela Moledo de Vasconcelos ${ }^{1}$

Rinaldini Coralini Philippo Tancredi ${ }^{2}$

Victor Augustus Marin ${ }^{3}$

${ }^{1}$ Programa de Pós-

Graduação em Vigilância

Sanitária, Instituto Nacional de Controle de Qualidade em Saúde, Fundação Oswaldo

Cruz. Av. Brasil 4365,

Manguinhos. 21.040-900

Rio de Janeiro RJ Brasil.

rafamoledo@gmail.com

${ }^{2}$ Escola de Nutrição, Centro

de Ciências Biológicas e da

Saúde,Universidade Federal

do Estado do Rio de Janeiro.

${ }^{3}$ Departamento de

Tecnologia dos Alimentos,

Universidade Federal do

Rio de Janeiro.

\begin{abstract}
Day care centers were first established in Brazil with the aim of reducing infant mortality rates, however the incidence of foodborne disease transmission has been on the increase. The World Health Organization (WHO) estimates that each year 1.8 million deaths worldwide occur in children under 5 years of age, which is attributed to the consumption of contaminated food. However, Brazilian legislation does not provide specific rules of operation for day care center kitchens. Thus, the scope of this study is to research the standards relating to the operation of day care centers, discussing the health regulations related to food production. By means of a review of electronic pages of various government organs, the regulations inherent to the operation and production of food in day care centers were examined. After scrutiny of the twenty-seven pieces of legislation found, there is a concern with water quality, supply of food, the control of pests and vectors, structural conditions and food policies. In spite of this, it was seen that not all the surveillance policies for the quality of food offered in day care centers are effective. Also observed was the lack of a specific regulation that establishes the quality criteria for safe handling of food in day care centers.
\end{abstract}

Key words Day care centers, Diseases, Children, Regulations, Quality
Resumo As primeiras creches foram instaladas no Brasil para reduzir os indices de mortalidade infantil, porém as Doenças Transmitidas por Alimentos vêm aumentando. A Organização Mundial da Saúde (OMS) estima que anualmente ocorram 1,8 milhões de mortes de crianças menores de 5 anos de idade em todo mundo, atribuidas ao consumo de alimentos contaminados. Entretanto, a legislação brasileira não prevê normas específicas de funcionamento para cozinhas de creches. Sendo assim, o objetivo desse estudo é pesquisar as normativas relacionadas ao funcionamento das creches, discutindo os regulamentos sanitários pertinentes à produção de alimentos. Através de uma revisão em páginas eletrônicas de diversos Órgãos, foram levantados regulamentos inerentes ao funcionamento e produção de alimentos em creches. Considerando as vinte e sete legislações encontradas, observa-se uma preocupação com a água, o fornecimento de gêneros, o controle de pragas e vetores, as condições estruturais e as politicas de Alimentação. Apesar disso, nota-se que nem sempre as politicas de vigilância da qualidade da alimentação oferecida nas creches são efetivas, assim como se percebe a ausência de um regulamento especifico que determine os critérios de qualidade para uma manipulação segura de alimentos nesses locais.

Palavras-chave Creches, Doenças, Crianças, Regulamentos, Qualidade 


\section{Introdução}

\section{O surgimento das creches}

Durante muito tempo o cuidado e a educação da criança eram considerados como de responsabilidade da família, porém surge a necessidade de instituições que assumissem esse papel, pelo menos enquanto seus pais estivessem no trabalho. Com a Revolução Industrial no século XIX, a estrutura familiar tradicional que cuidava dos filhos pequenos foi modificada, com a entrada da mulher e de outros membros no mercado de trabalho, na busca de garantir sua subsistência ${ }^{1}$.

Antigamente, a mãe operária procurava trabalho como recurso para aumentar a renda familiar e se afastava, por esse motivo, do convívio de seus filhos. Hoje, também algumas mulheres de classe média, procuram o trabalho como fonte de renda ou motivo de afirmação pessoal. A exiguidade dos espaços e moradias urbanas, no entanto, acrescida da falta de avós e tias que, no início do século, habitavam a casa grande junto à família e participavam dos afazeres domésticos e da guarda e educação das crianças e que hoje também já se incorporam à população ativa, é o novo fator responsável pela procura de creches. Esta nova classe social, mais exigente com os cuidados de seus filhos, acabou por conseguir que se incluíssem às responsabilidades de abrigo, higiene e alimentação, antes oferecidos pelas creches às crianças pobres, os cuidados psicopedagógicos só encontrados nos jardins de infância, pré-escolas e escolas maternais, disponíveis, na sua maioria, exclusivamente, às classes mais ricas².

Da mesma forma como aconteceu em vários países, a alimentação escolar no Brasil, como instrumento de política pública de alimentação e nutrição, originou-se a partir de uma necessidade maior do Estado de solucionar o problema da fome ${ }^{3}$.

No Brasil as primeiras instituições instaladas foram criadas por iniciativa privada. Em 1899 fundaram o Instituto de Proteção e Assistência à Infância, com sede no Rio de Janeiro, que entre os seus objetivos estava o de atender as crianças menores de oito anos; atender às crianças pobres, doentes, defeituosas, maltratadas e moralmente abandonadas; criando creches, maternidades e jardins de infância. Em 1908, teve início a primeira creche popular, dirigida aos filhos dos operários até dois anos. No período da república, criam-se as primeiras instituições, chegando a contar ao menos 15 creches, em 1921, e 47, em
1924, distribuídas por várias capitais e algumas cidades do país ${ }^{2}$.

O objetivo principal das primeiras creches instaladas no Brasil era o de reduzir os enormes índices de mortalidade infantil, através do fornecimento de abrigo, alimentação e alguns cuidados médico-higiênicos para as crianças. Com o tempo, elas passam a também liberar a força de trabalho feminina ${ }^{2}$.

Em países desenvolvidos e em desenvolvimento, o uso de serviços de cuidado infantil está cada vez mais comum. No Brasil, nas médias e grandes cidades, 10 a $15 \%$ dos pré-escolares frequentam creches gratuitas ${ }^{4}$. De acordo com Rizzo $^{2}$, a Constituição de 1988 reconheceu como um direito da criança e um dever do Estado, o acesso à educação em creches e pré-escolas. Mesmo assim, a luta ainda é muito grande para as mulheres trabalhadoras, de classes mais populares, conseguirem dar atenção aos seus filhos enquanto trabalham, assim como obter um acesso irrestrito, de qualidade, às atuais creches.

A Organização Mundial da Saúde (OMS) junto com as demais organizações das Nações Unidas, responsáveis pela nutrição e saúde da população mundial, afirmam que a boa nutrição deve ter início ainda na vida intrauterina, se estendendo pela infância, período considerado crítico para assegurar o crescimento adequado do ser humano ${ }^{5}$.

Como o desenvolvimento infantil acontece de forma dinâmica, é nos primeiros anos de vida que as crianças precisam receber os cuidados necessários para o pleno desenvolvimento biopsico-social e, mais tarde, para se tornarem jovens e adultos saudáveis, com conhecimento necessário para que possam viver em harmonia no seu grupo social e com capacidade suficiente para um melhor desempenho no trabalho ${ }^{6}$.

O bem-estar da criança está pautado em três fatores principais: a alimentação, os cuidados e o ambiente onde está inserida. Se algum desses aspectos está comprometido por condições desfavoráveis, uma das consequências mais imediatas pode ser a perda da saúde, que repercute de forma bastante negativa sobre o desenvolvimento humano ${ }^{5}$.

\section{A alimentação da criança}

A nutrição e a alimentação visam o desenvolvimento integral da criança, constituindo alguns dos requisitos para a promoção e a proteção da saúde, possibilitando um bom crescimento e desenvolvimento humano ${ }^{7}$.

A alimentação escolar constitui-se como um dos direitos fundamentais do cidadão, sendo 
previsto na Constituição Federal. No intuito de garantir este direito, o Programa Nacional de Alimentação Escolar (PNAE) foi criado como instrumento oficial do Governo Federal ${ }^{8}$.

Os beneficiários do PNAE são os alunos matriculados na educação infantil, oferecida em creches e pré-escolas, e no ensino fundamental da rede pública de ensino dos estados, do Distrito Federal e dos municípios, ou em estabelecimentos mantidos pela União, que constam no censo escolar realizado pelo Ministério da Educação no ano anterior ao do atendimento?

O Programa de Alimentação destinado às Creches tem como objetivo garantir às crianças matriculadas nestas o acesso à alimentação saudável, visando à promoção da saúde e o pleno desenvolvimento deste segmento da população ${ }^{10}$.

O reconhecimento da importância social desse Programa baseia-se em que as satisfatórias condições de saúde e nutrição são requisitos essenciais para o rendimento escolar, pelo que se constitui como uma das políticas sociais mais relevantes, quando colocamos o fato de que para milhões de crianças a alimentação escolar é fundamental para ajudar a suprir suas necessidades proteicas e calóricas mínimas e muitas vezes a única comida da criança durante o dia9.

A alimentação escolar deve ser de boa qualidade, não somente nos valores nutricionais, mas também no aspecto da higiene. Este fato é de particular importância, pois as crianças, devido ao fato de não possuírem ainda o sistema imunológico totalmente desenvolvido, são mais susceptíveis às enfermidades transmitidas por alimentos, provocadas por perigos biológicos, químicos ou físicos ${ }^{11}$. Segundo Mascarini e Donalí$\mathrm{sio}^{12}$, a criança usuária de creche tem maior probabilidade de adquirir e desenvolver infecções, sobretudo as de repetição, como as respiratórias, gastrointenstinais e cutâneas.

\section{Doenças Transmitidas por Alimentos (DTA)}

A ocorrência de DTA vem aumentando de modo significativo em nível mundial. Vários são os fatores que contribuem para a emergência dessas doenças, dentre os quais se destacam: o crescente aumento das populações, a existência de grupos populacionais vulneráveis ou mais expostos, o processo de urbanização desordenado e a necessidade de produção de alimentos em grande escala. Contribui ainda, o deficiente controle dos órgãos públicos e privados, no tocante à qualidade dos alimentos ofertados às populações ${ }^{13}$.

As DTA são todas as ocorrências clínicas consequentes da ingestão de alimentos que possam estar contaminados com microrganismos patogênicos, substâncias químicas, objetos lesivos ou que contenham em sua constituição substâncias naturalmente tóxicas. Os alimentos podem ter como fontes de contaminação os equipamentos e os utensílios que entram em contato com os alimentos, as mãos dos manipuladores e a água ${ }^{14}$.

Para atender à legislação brasileira e evitar a veiculação de microrganismos patogênicos que colocam em risco a saúde dos usuários, deve-se controlar a contaminação, a multiplicação e a sobrevivência microbiana nos diversos ambientes. Uma forma de reduzir os riscos à saúde é a adoção das Boas Práticas em todos os locais que manipulam alimentos, reduzindo assim, os riscos de DTA $^{14}$.

De acordo com a Secretaria de Vigilância em Saúde do Ministério da Saúde ${ }^{15}$, de 1999 a 2008 foram notificados 6.062 surtos de DTA, envolvendo 117.330 pessoas doentes e 64 óbitos. Dos 2.974 surtos que tiveram agentes etiológicos conhecidos, as causas foram: bactérias (84\%), vírus $(13,6 \%)$, parasitas (1\%), químicos $(1,4 \%)$. Os agentes bacterianos mais frequentes foram: Salmonella spp (42,9\%), Staphylococcus sp (20,2\%), Bacillus cereus (6,9\%), Clostridium perfringens (4,9\%), Salmonella Enteritidis (4,0\%), Shigella sp $(2,7 \%)$, outros $(18,4 \%)$. Os alimentos mais comumente envolvidos foram: ovos crus e mal cozidos $(22,8 \%)$, alimentos mistos $(16,8 \%)$, carnes vermelhas $(11,7 \%)$, sobremesas $(10,9 \%)$, água $(8,8 \%)$, leite e derivados $(7,1 \%)$, outros $(21,8 \%)$. As instituições de ensino ocuparam o terceiro lugar no ranking dos locais de ocorrência de surtos, atrás apenas das residências e restaurantes.

A OMS estima que anualmente ocorram 1,2 bilhões de episódios de diarreia e cerca de 2,2 milhões de óbitos atribuídos ao consumo de alimentos contaminados, sendo que 1,8 milhões dessas mortes em todo mundo são de crianças menores de 5 anos de idade ${ }^{16}$.

Os riscos de contaminação nas creches e escolas são maiores devido ao preparo dos alimentos com muita antecedência, o que favorece a exposição prolongada a eventuais agentes contaminantes. Além disso, as condições de higiene inadequadas no local de preparo e distribuição também contribuem para isso ${ }^{17}$. As refeições são preparadas em grande quantidade e, até o momento da distribuição, em sua maioria, permanecem expostas à temperatura ambiente ${ }^{18}$.

Essa inadequada preparação de alimentos implica em riscos para as crianças e funcionários em geral, sendo de grande importância a utilização de medidas profiláticas para a diminuição deste 
problema, através dos aspectos higiênico-sanitários no preparo do alimento, treinamento de pessoal e a informação da educação sanitária ${ }^{19}$.

A legislação brasileira não prevê normas específicas de funcionamento para cozinhas de creches ou qualquer outra instituição de ensino. As normas utilizadas no controle de funcionamento de cozinhas em creches são as mesmas que determinam o funcionamento e estrutura de outros tipos de serviços ${ }^{17}$.

Atualmente a crescente preocupação coletiva pelo consumo de alimentos seguros é um dos maiores desafios que se enfrenta. A implantação de um Sistema de Segurança Alimentar é uma aproximação para prevenir a possibilidade de produzir alimentos inseguros que causem danos à saúde ${ }^{19}$.

\section{Objetivo}

Pesquisar as normativas relacionadas ao funcionamento das creches, discutindo os regulamentos sanitários pertinentes à produção de alimentos.

\section{Metodologia}

Através de uma pesquisa em páginas eletrônicas de diversos órgãos, entre os anos de 2009 e 2012, foram levantados regulamentos inerentes ao funcionamento e produção de alimentos em creches. Foram consultadas as bases on-line de órgãos como: Agência Nacional de Vigilância Sanitária, Prefeitura da Cidade do Rio de Janeiro, Câmara Municipal do Rio de Janeiro, Presidência da República Federativa do Brasil; assim como os portais das Leis Municipais e JusBrasil.

Os regulamentos foram organizados em quatro blocos: Leis, Decretos, Resoluções e Portarias, considerando os órgãos de origem e disposição. Os dados foram analisados em Microsoft Excel 2010.

\section{Resultados e discussão}

Foram pesquisadas as regulamentações (Leis, Decretos, Resoluções e Portarias) referentes às creches, que estão apresentadas nos Quadros 1 ao 4 .

Foram encontradas oito Leis $(30 \%)$ originadas do Município do Rio de Janeiro, do Estado do Rio de Janeiro e do Congresso Nacional, dos anos de 1985 a 2009, que foram obtidas nas bases on-line da Câmara Municipal do Rio de Ja- neiro, Prefeitura da Cidade do Rio de Janeiro, Presidência da República Federativa do Brasil e no portal das Leis Municipais (Quadro 1). As Leis que emanam do poder legislativo, Câmara de Senadores, Deputados e Vereadores, estabelecem uma regra, um direito ou uma exceção de caráter geral ou específico ${ }^{46}$. Estas Leis dispõem sobre as condições higiênico-sanitárias: desinsetização e desratização, monitoramento da água, limpeza das caixas de gordura, curso de noções de higiene; e políticas: Sistema Estadual de Creches, qualificação de Merendeiras, Sistema Nacional de Segurança Alimentar e Nutricional (SISAN) e Programa de Alimentação Escolar.

Foram encontrados nove Decretos (33\%) originados do Município do Rio de Janeiro, dos anos de 1956 a 2008, que foram obtidos na base online da Prefeitura da Cidade do Rio de Janeiro e nos portais das Leis Municipais e JusBrasil (Quadro 2). Os Decretos são de competência exclusiva dos Chefes do Executivo (Presidente, Governadores e Prefeitos), e regulamentam os assuntos relacionados às leis existentes; é a determinação formal da autoridade ${ }^{20}$. Os Decretos dispõem sobre as condições higiênico-sanitárias: Regulamento da Defesa e Proteção da Saúde, empresas fornecedoras de gêneros, curso de Noções Básicas em Manipulação; as condições estruturais: critérios para o licenciamento de edificações; e políticas: setor de Alimentação do Escolar, Instituto de Nutrição Annes Dias, oferta de determinados alimentos em Unidades Escolares, Serviço de Vigilância Sanitária em Creches e Escolas.

Foram encontradas seis Resoluções (22\%) originadas do Município do Rio de Janeiro e do Ministério da Saúde, dos anos de 2001 a 2008, que foram obtidas na base on-line da Prefeitura da Cidade do Rio de Janeiro e da Agência Nacional de Vigilância Sanitária (Quadro 3). As Resoluções são de competência de autoridades outras que não o Chefe do Executivo (Ministros/Secretários/Colegiados); são atos com que se formalizam as decisões de Órgão Colegiado, com instruções quanto à aplicação de leis ou regulamentos impondo uma ordem ou estabelecendo medidas ${ }^{46}$. Essas Resoluções dispõem sobre as condições higiênico-sanitárias: limpeza e desinfecção de caixas d'água e cisternas, veículos de transporte de alimentos, fornecimento de gêneros alimentícios; as condições estruturais: planejamento, programação, elaboração e avaliação de projetos físicos; e políticas: Programa de Qualidade da Água e Alimentos, funcionamento de creches públicas.

Foram encontradas quatro Portarias (15\%) originadas do Ministério da Saúde e do Ministé- 
Quadro 1. Leis referentes a creches municipais do Rio de Janeiro.

\begin{tabular}{|c|c|}
\hline No, data e origem & Disposição \\
\hline $\begin{array}{c}\text { No } 837-23 / 01 / 1985^{20} \\
\text { Secretaria Estadual de Saúde do Rio de } \\
\text { Janeiro (Assembleia Legislativa do Estado do } \\
\text { Rio de Janeiro) }\end{array}$ & Dispõe sobre a legislação do sistema estadual de creches. \\
\hline $\begin{array}{l}\text { No } 1353-10 / 11 / 1988^{21} \\
\text { (Prefeitura do Rio de Janeiro) }\end{array}$ & $\begin{array}{l}\text { Dispõe sobre a obrigatoriedade de desinsetização e } \\
\text { desratização em creches etc. }\end{array}$ \\
\hline $\begin{array}{l}\text { No } 1662-23 / 01 / 1991^{22} \\
\text { (Prefeitura do Rio de Janeiro) }\end{array}$ & $\begin{array}{l}\text { Dispõe sobre a obrigatoriedade de frequência a curso de } \\
\text { noções de higiene nas condições que menciona. }\end{array}$ \\
\hline $\begin{array}{c}\text { No } 3401-20 / 05 / 2002^{23} \\
\text { (Prefeitura do Rio de Janeiro) }\end{array}$ & $\begin{array}{l}\text { Altera a qualificação essencial da categoria funcional de } \\
\text { Merendeira. }\end{array}$ \\
\hline $\begin{array}{l}\qquad \mathrm{N}^{\circ} 3.52707 / 04 / 2003^{24} \\
\text { Secretaria Municipal de Saúde do Rio de } \\
\text { Janeiro (Câmara Municipal do Rio de Janeiro) }\end{array}$ & $\begin{array}{l}\text { Monitoramento da água utilizada em estabelecimentos de } \\
\text { ensino e saúde. }\end{array}$ \\
\hline $\begin{array}{c}\text { No } 11.346-15 / 09 / 2006^{25} \\
\text { (Presidência da República - Congresso } \\
\text { Nacional) }\end{array}$ & $\begin{array}{l}\text { Cria o Sistema Nacional de Segurança Alimentar e } \\
\text { Nutricional (SISAN) com vistas em assegurar o direito } \\
\text { humano à alimentação adequada e dá outras providências. }\end{array}$ \\
\hline $\begin{array}{l}\text { Lei Ordinária No } 4.991-22 / 01 / 2009^{26} \\
\text { (Prefeitura do Rio de Janeiro) }\end{array}$ & $\begin{array}{l}\text { Dispõe sobre a obrigatoriedade da limpeza das caixas de } \\
\text { gordura nas edificações do município do RJ. }\end{array}$ \\
\hline $\begin{array}{c}\text { No } 11.947-16 / 06 / 2009^{27} \\
\text { (Presidência da República - Congresso } \\
\text { Nacional) }\end{array}$ & Novas diretrizes do Programa de Alimentação Escolar. \\
\hline
\end{tabular}

Fonte: Elaboração própria.

rio de Educação, dos anos de 1988 a 2006, que foram obtidas na base on-line da Agência Nacional de Vigilância Sanitária (Quadro 4). As Portarias são de competência de autoridades outras que não o Chefe do Executivo (Chefes de Órgãos, Repartições ou Serviços); formalizam os atos administrativos: nomeações, designações, sindicâncias, inquéritos ou processos ${ }^{46}$. Essas Portarias dispõem sobre as condições higiênicosanitárias: controle e vigilância da qualidade da água; as condições estruturais: normas para construção e funcionamento de creches; e as políticas: Política Nacional de Alimentação e Nutrição e Promoção da Alimentação Saudável.

Dentre as vinte e sete legislações encontradas neste estudo, observou-se que mais de $70 \%$ foram elaboradas somente a partir do ano 2000, apesar das creches terem sido criadas décadas antes. Nestes regulamentos, pôde-se observar uma preocupação com a qualidade da água, o fornecimento de gêneros por empresas, assim como o controle de pragas e vetores. Também existe a abordagem de algumas condições estruturais, de políticas de Alimentação e a determinação de responsabilidade dos Órgãos envolvidos.

Apesar de essas legislações estarem relacionadas às creches, percebe-se a ausência de um regulamento específico que determine os critérios de qualidade para uma manipulação segura de alimentos nesses locais.

Considerando isso, pode-se destacar alguns regulamentos que são direcionados às condições higiênico-sanitárias e de Boas Práticas em Indústrias e Serviços de Alimentação, e que se tornam aplicáveis às creches devido a ausência de legislação específica:

- Portaria MS No 1428, de 26 de novembro de 1993, que aprova o Regulamento Técnico para Inspeção Sanitária de Alimentos, Diretrizes para o Estabelecimento de Boas Práticas de Produção e de Prestação de Serviços na Área de Alimentos, Regulamento Técnico para o Estabelecimento de Padrão de Identidade e Qualidade (PIQ) para Serviços e Produtos na Área de Alimentos ${ }^{19}$; 
Quadro 2. Decretos referentes a creches municipais do Rio de Janeiro.

\begin{tabular}{|c|c|}
\hline No, data e origem & Disposição \\
\hline $\begin{array}{c}\mathrm{N}^{\circ} 13.355-13 / 10 / 1956^{28} \\
\text { (Prefeitura do Rio de Janeiro) }\end{array}$ & $\begin{array}{l}\text { Subordina o setor de Alimentação do Escolar a Secretaria } \\
\text { Geral de Educação e Cultura. Profissões afins ao Instituto: } \\
\text { professores, médicos, nutricionistas, atendentes, assistente } \\
\text { social, entre outros. }\end{array}$ \\
\hline $\begin{array}{l}\text { No } 6.235-30 / 10 / 1986^{29} \\
\text { Secretaria Municipal de Saúde do Rio de } \\
\text { Janeiro (Prefeitura do Rio de Janeiro) }\end{array}$ & $\begin{array}{l}\text { Aprova o Regulamento da Defesa e Proteção da Saúde no } \\
\text { tocante a alimentos e à Higiene Habitacional e Ambiental. }\end{array}$ \\
\hline $\begin{array}{l}\text { No } 15.411-20 / 12 / 1996^{30} \\
\text { Secretaria Municipal de Saúde do Rio de } \\
\text { Janeiro (Prefeitura do Rio de Janeiro) }\end{array}$ & $\begin{array}{l}\text { Consolida a Organização Básica do Poder Executivo } \\
\text { Municipal como as atribuições do Instituto de Nutrição } \\
\text { Annes Dias. }\end{array}$ \\
\hline $\begin{array}{l}\mathrm{N}^{\circ} 21.217-01 / 04 / 2002^{31} \\
\text { Secretaria Municipal de Educação do Rio } \\
\text { de Janeiro (Prefeitura do Rio de Janeiro) }\end{array}$ & $\begin{array}{l}\text { Pró́be, no âmbito das Unidades Escolares da rede } \\
\text { municipal de ensino, adquirir, confeccionar, distribuir e } \\
\text { consumir os produtos como balas, doces a base de goma, } \\
\text { gomas de mascar etc. }\end{array}$ \\
\hline $\begin{array}{l}\text { No } 21.585-19 / 06 / 2002^{32} \\
\text { Secretaria Municipal de Saúde do Rio de } \\
\text { Janeiro (Prefeitura do Rio de Janeiro) }\end{array}$ & $\begin{array}{l}\text { Procedimento a ser adotado nas vistorias em empresas } \\
\text { interessadas no fornecimento de gêneros alimentícios no } \\
\text { âmbito municipal. }\end{array}$ \\
\hline $\begin{array}{c}\mathrm{N}^{\circ} 25.673-17 / 08 / 2005^{33} \\
\text { (Prefeitura do Rio de Janeiro) }\end{array}$ & $\begin{array}{l}\text { Novos critérios para o Curso de Noções Básicas em } \\
\text { Manipulação de Alimentos. }\end{array}$ \\
\hline $\begin{array}{l}\text { No } 26.286-24 / 03 / 2006^{34} \\
\text { (Prefeitura do Rio de Janeiro) }\end{array}$ & $\begin{array}{l}\text { Altera a estrutura organizacional da Superintendência de } \\
\text { Controle de Zoonoses, Vigilância e Fiscalização Sanitária as } \\
\text { Secretaria Municipal de Saúde (Serviço de Vigilância } \\
\text { Sanitária em Creches e Escolas). }\end{array}$ \\
\hline $\begin{array}{l}\text { No } 29.569-08 / 07 / 2008^{35} \\
\text { (Prefeitura do Rio de Janeiro) }\end{array}$ & $\begin{array}{l}\text { Estabelece procedimento a ser adotado nas vistorias em } \\
\text { empresas interessadas no fornecimento de gêneros } \\
\text { alimentícios no âmbito municipal. }\end{array}$ \\
\hline $\begin{array}{l}\text { No } 29.687-12 / 08 / 2008^{36} \\
\text { (Prefeitura do Rio de Janeiro) }\end{array}$ & $\begin{array}{l}\text { Estabelece os critérios para o licenciamento de edificações } \\
\text { destinadas às escolas e creches da rede pública municipal. }\end{array}$ \\
\hline
\end{tabular}

Fonte: Elaboração própria.

- Portaria SVS/MS No 326, de 30 de julho de 1997, que aprova o Regulamento Técnico sobre as Condições Higiênico-Sanitárias e de Boas Práticas de Fabricação para Estabelecimentos Produtores/Industrializadores de Alimentos ${ }^{46}$;

- Resolução - RDC No 275, de 21 de outubro de 2002 que dispõe sobre o Regulamento Técnico de Procedimentos Operacionais Padronizados aplicados aos Estabelecimentos Produtores/Industrializadores de Alimentos e a Lista de Verificação das Boas Práticas de Fabricação em Estabelecimentos Produtores/Industrializadores de Alimentos ${ }^{47}$;

- Resolução - RDC No 216, de 15 de setembro de 2004 que dispõe sobre o Regulamento
Técnico de Boas Práticas para Serviços de Alimentação ${ }^{48}$.

Essas quatro últimas legislações descritas foram originadas do Ministério da Saúde, dos anos de 1993 a 2004, e obtidas na base on-line da Agência Nacional de Vigilância Sanitária.

A Portaria No $1428^{19}$ foi criada em 1993 visando à melhoria da qualidade de vida, proteção de saúde, fiscalização sanitária dos alimentos e avaliações de risco epidemiológico. Em 1997, a Portaria No $326^{46}$ foi elaborada tendo em vista a necessidade de aperfeiçoamento das ações de controle sanitário na área de alimentos visando à proteção da saúde da população e a importância 
Quadro 3. Resoluções referentes a creches municipais do Rio de Janeiro.

\begin{tabular}{|c|c|}
\hline $\mathrm{N}^{\circ}$, data e origem & Disposição \\
\hline $\begin{array}{l}\quad \mathrm{N}^{\circ} 752-10 / 01 / 2001^{37} \\
\text { Secretaria Municipal de Saúde do Rio de } \\
\text { Janeiro(Prefeitura do Rio de Janeiro) }\end{array}$ & $\begin{array}{l}\text { Dispõe sobre a limpeza e desinfecção de caixas d'águas e } \\
\text { de cisternas }\end{array}$ \\
\hline $\begin{array}{l}\text { No } 50-21 / 02 / 2002^{38} \\
\text { Agência Nacional de Vigilância Sanitária } \\
\text { (Ministério da Saúde) }\end{array}$ & $\begin{array}{l}\text { Regulamento Técnico para planejamento, programação, } \\
\text { elaboração e avaliação de projetos físicos de } \\
\text { estabelecimentos assistenciais de saúde. }\end{array}$ \\
\hline $\begin{array}{l}\text { No } 604-11 / 09 / 2002^{39} \\
\text { (Prefeitura do Rio de Janeiro) }\end{array}$ & $\begin{array}{l}\text { Regulamenta os veículos de transporte de alimentos } \\
\text { destinados ao consumo humano, refrigerados ou não, em } \\
\text { condições seguras. }\end{array}$ \\
\hline $\begin{array}{l}\text { No } 8-12 / 12 / 2002^{40} \\
\text { Secretaria Municipal de Educação do Rio } \\
\text { de Janeiro (Prefeitura do Rio de Janeiro) }\end{array}$ & $\begin{array}{l}\text { Institui o Programa de Qualidade de Água e Alimentos em } \\
\text { Escolas e Creches. }\end{array}$ \\
\hline $\begin{array}{l}\text { No } 849-05 / 11 / 2004^{41} \\
\text { Secretaria Municipal de Educação do Rio } \\
\text { de Janeiro (Prefeitura do Rio de Janeiro) }\end{array}$ & $\begin{array}{l}\text { Altera e revoga dispositivos da Resolução SME No } 816 \text { de } \\
05 / 01 / 2004 \text {, esta que normatiza o funcionamento das } \\
\text { creches públicas do Sistema Municipal de ensino e dá } \\
\text { outras providências. }\end{array}$ \\
\hline $\begin{array}{l}\text { No } 1370-31 / 07 / 2008^{42} \\
\text { Secretaria Municipal de Saúde do Rio de } \\
\text { Janeiro (Prefeitura do Rio de Janeiro) }\end{array}$ & $\begin{array}{l}\text { Fornecimento de gêneros alimentícios por firmas } \\
\text { interessadas. }\end{array}$ \\
\hline
\end{tabular}

Fonte: Elaboração própria, a partir de várias resoluções listadas nas referências (http://www.anvisa.gov.br; http:// www.rio.rj.gov.br).

Quadro 4. Portarias referentes a creches municipais do Rio de Janeiro.

\begin{tabular}{|c|c|}
\hline No, data e origem & \multicolumn{1}{c|}{ Disposição } \\
\hline $\begin{array}{c}\text { No } 321-26 / 05 / 1988^{43} \\
\text { (Ministério da Saúde) }\end{array}$ & $\begin{array}{l}\text { Aprova as normas e os padrões mínimos que disciplinam a } \\
\text { construção, instalação e o funcionamento de creches. }\end{array}$ \\
\hline $\begin{array}{l}\text { No } 710-10 / 06 / 1999^{7} \\
(\text { Ministério da Saúde })\end{array}$ & Política Nacional de Alimentação e Nutrição. \\
\hline $\begin{array}{c}\text { No } 518-25 / 03 / 2004^{44} \\
(\text { Ministério da Saúde })\end{array}$ & $\begin{array}{l}\text { Estabelece os procedimentos e responsabilidades relativos ao } \\
\text { controle e vigilância da qualidade da água para o consumo } \\
\text { humano e seu padrão de potabilidade, e dá outras providências. }\end{array}$ \\
\hline $\begin{array}{c}\text { No1010 - 08/05/2006 } \\
\text { Ministério da Saúde e Ministério da } \\
\text { Educação })\end{array}$ & $\begin{array}{l}\text { Institui as diretrizes para a Promoção da Alimentação Saudável } \\
\text { nas Escolas da educação infantil, fundamental e nível médio das } \\
\text { redes públicas e privadas, em âmbito nacional. }\end{array}$ \\
\hline
\end{tabular}

Fonte: Elaboração própria

de compatibilizar a legislação Nacional com base nos instrumentos harmonizados no Mercosul com relação às condições higiênico-sanitárias.

A Resolução No $275^{47}$ foi criada em 2002 diante da constante necessidade de aperfeiçoamento de ações de controle sanitário, e de harmonização da ação de inspeção sanitária em Estabelecimentos Produtores/Industrializadores de alimentos em todo território Nacional, e também pela necessidade de complementar a Portaria No $326^{46}$. 
E por último, em 2004, a Resolução No $216^{48}$ foi elaborada considerando-se também a necessidade de constante aperfeiçoamento das ações de controle sanitário na área de alimentos visando à proteção da saúde da população e à harmonização da ação de inspeção sanitária em Serviços de Alimentação, assim como a necessidade de elaboração de requisitos higiênico-sanitários gerais para Serviços de Alimentação aplicados em todo território Nacional.

Além desses regulamentos, pode-se destacar a existência de Manuais/Guias de relevância no âmbito da Vigilância Sanitária, como: "Manual do Preparador e Manipulador de Alimentos", de 2002, da Secretaria Municipal de Saúde/Secretaria Municipal de Educação ${ }^{6}$, e o "Manual Integrado de Prevenção e Controle de Doenças Transmitidas por Alimentos", de 2010, do Ministério da Saúde ${ }^{49}$. O objetivo do primeiro Manual é contribuir para a formação do manipulador de alimentos, além de colaborar para o planejamento de um fluxo de trabalho saudável para os funcionários do Serviço de Alimentação e Nutrição. O segundo Manual reúne informações da vigilância epidemiológica, vigilância sanitária, vigilância ambiental, assistência em saúde, defesa e inspeção agropecuária, laboratório e outras áreas e instituições necessárias para investigação, controle e prevenção dos casos e surtos das doenças transmitidas por alimentos, contribuindo para a melhoria da qualidade de vida da população.

\section{Colaboradores}

RM Vasconcelos trabalhou na pesquisa e concepção do texto, RCP Tancredi trabalhou na pesquisa e na metodologia, e VA Marin trabalhou na revisão final.

\section{Agradecimentos}

À Coordenação de Aperfeiçoamento de Pessoal de Nível Superior (CAPES) como órgão de fomento e a Pós-Graduação em Vigilância Sanitária INCQS/FIOCRUZ.
Considerando os regulamentos existentes, específicos ou não para creches, nota-se que nem sempre as políticas de vigilância da qualidade da alimentação oferecida nestas são efetivas. Muito se diz sobre obrigatoriedades, critérios/parâmetros, determinação de responsabilidades, visando o direito à alimentação de todo ser humano, porém não necessariamente acontece dessa forma no dia-a-dia.

Entretanto, o objetivo final das políticas e normativas é conhecer o problema e sua magnitude, subsidiando as medidas de prevenção e controle, visando reduzir a incidência de DTA. Assim, considerando-se as necessidades descritas pelos Órgãos responsáveis para elaboração de Regulamentos Técnicos, a falta de legislação específica, a vulnerabilidade da população-alvo atendida, o tipo de Serviço de Alimentação das creches, e ainda a necessidade de constante aperfeiçoamento das ações de controle sanitário na área de alimentos visando à proteção da saúde da população infantil, também tendo em vista a necessidade de harmonização da ação de inspeção sanitária em Serviços de Alimentação Infantil, a necessidade de complementar a Resolução No $216^{48}$ para elaboração de requisitos higiênico-sanitários específicos para estabelecimentos que confeccionam alimentação infantil, sugere-se a elaboração de um Regulamento Técnico de Boas Práticas e Procedimentos Operacionais Padronizados aplicados aos Serviços de Alimentação Infantil - as Creches.

\section{Referências}

1. Ruiz JS. Creche: Um Discurso acerca de seu Surgimento. In: Anais do Encontro de Pedagogia: 40 Anos formando Educadores; 2007; Corumbá. p. 98-108.

2. Rizzo G. Creche: Organização, Currículo, Montagem e Funcionamento. 3a Edição. Rio de Janeiro: Bertrand Brasil; 2003.

3. Turpin ME. A Alimentação Escolar como Vetor de Desenvolvimento Local e Garantia de Segurança Alimentar e Nutricional [dissertação]. Campinas: Universidade Estadual de Campinas; 2008.

4. Barros AJD, Gonçalves EV, Borba CRS, Lorenzatto CS, Motta DB, Silva VRL, Schiroky V M. Perfil das creches de uma cidade de porte médio do sul do Brasil: operação, cuidados, estrutura física e segurança. Cad Saude Publica 1999; 15(Supl. 3):597-604.

5. Cavalcante AAM. Consumo alimentar, perfil nutricional e de saúde de crianças do $2^{\circ}$ e $3^{\circ}$ anos de vida atendidas em serviços públicos de saúde do município de Viçosa - Minas Gerais [tese]. Minas Gerais: Universidade Federal de Viçosa; 2004. 
6. Rio de Janeiro (Município). Prefeitura da Cidade do Rio de Janeiro. Secretaria Municipal de Saúde. Secretaria Municipal de Educação. Manual do preparador e manipulador de alimentos; 2002. [página na Internet]. [acessado $2011 \mathrm{fev} 28$ ]. Disponível em: http://www.rio.rj.gov.br.

7. Brasil. Portaria $\mathrm{n}^{\circ} 710$ de 10 de junho de 1999. Dispõe sobre a Política Nacional de Alimentação e Nutrição. Diário Oficial da União 1999; 15 jun.

8. Dias MRM, Vieira A M, Caixêta EM, Monego ET, Freitas GS, Corrêa MHS, Brito MCM, Campos MRH, Santiago RAC. Avaliação e monitoramento da qualidade dos alimentos oferecidos na merenda escolar. Goiânia, Goiás: Faculdade de Nutrição - Núcleo de Estudos e Pesquisa Aplicadas à Alimentação e Nutrição - Centro Colaborador em Alimentação e Nutrição; Superintendência de Vigilância Sanitária - Gerência de Desenvolvimento Técnico em Produtos; Secretaria de Estado da Saúde, Sistema Único de Saúde; 2004. [página na Internet]. [acessado 23 jun 2008]. Disponível em: http://www. visa.goias.gov.br

9. Pedraza DF, Andrade SLLS. A alimentação escolar analisada no contexto de um Programa de Alimentação e Nutrição. RBPS 2006; 19(Supl. 3):164-174.

10. Rio de Janeiro (Município). Instituto de Nutrição Annes Dias (INAD). Prefeitura do Município do Rio de Janeiro. Secretaria Municipal de Saúde. Manual do Programa de Alimentação Escolar - Cardápios. Rio de Janeiro; INAD: 2005.

11. Silva C, Germano MIS, Germano PML. Condições higiênico-sanitárias dos locais de preparação da merenda escolar, da rede estadual de ensino em São Paulo, SP. Hig aliment, 2003; 17 (Supl. 110):49-55.

12. Mascarini LM, Donalísio MR. Giardíase e criptosporidiose em crianças institucionalizadas em creches no Estado de São Paulo. Rev Socied Bras Med Trop, 2009; 39(Supl. 6):577-579.

13. Brasil. Ministério da Saúde (MS). Secretaria de Vigilância em Saúde (SVS). Manual Integrado de Prevenção e Controle de Doenças Transmitidas por Alimentos. Brasília: MS, SVS; 2005.

14. Bastos CCB. Condições Higiênico-Sanitárias do Preparo de Refeições em Creches Comunitárias de Belo Horizonte, Minas Gerais [dissertação]. Minas Gerais: UFMG; 2008.

15. Brasil. Ministério da Saúde (MS). Secretaria de Vigilância em Saúde (SVS). Coordenação de Vigilância das Doenças de Transmissão Hídrica e Alimentar. Análise Epidemiológica dos Surtos de Doenças Transmitidas por Alimentos no Brasil. Brasília: MS; 2008.

16. Organização Pan-Americana da Saúde (OPAS), Organização Mundial da Saúde (OMS). Perspectiva sobre a análise de risco na segurança dos alimentos. Curso de Sensibilização. Área de Vigilância Sanitária, Prevenção e Controle de Doenças. Rio de Janeiro: OMS; 2008. [página na Internet]. [acessado 2009 maio 22]. Disponível em: http://www. panalimentos.org.br

17. Oliveira MN, Brasil ALD, Taddei JAAC. Avaliação das condições higiênico-sanitárias das cozinhas de creches públicas e filantrópicas. Cien Saude Colet, 2008; 13(Supl. 3):1051-1060.
18. Rosa MS, Negreiros SRF, Sebra LMJ, Stamford TLM. Monitoramento de tempo e temperatura de distribuição de preparações à base de carne em escolas municipais de Natal (RN). Rev Nut 2008; 21(Supl. 1):21-28.

19. Piragine KO. Aspectos higiênicos e sanitários do preparo da merenda escolar na rede estadual de ensino de Curitiba [dissertação]. Curitiba: Universidade Federal do Paraná; 2005.

20. Tancredi RCP. Aplicabilidade normativa nas ações desenvolvidas pela Vigilância Sanitária Municipal do Rio de Janeiro [tese]. Rio de Janeiro: Fundação Oswaldo Cruz; 2006.

21. Brasil. Portaria MS no 1428 de 26 de novembro de 1993. Dispõe sobre o Regulamento Técnico para Inspeção Sanitária de Alimentos, Diretrizes para o Estabelecimento de Boas Práticas de Produção e de Prestação de Serviços na Área de Alimentos, Regulamento Técnico para o Estabelecimento de $\mathrm{Pa}$ drão de Identidade e Qualidade (PIQ's) para Serviços e Produtos na Área de Alimentos. Diário Oficial da União 1993; 02 dez.

22. Rio de Janeiro. Lei no 837, de 23 de janeiro de 1985. Dispõe sobre a legislação do sistema estadual de creches. Diário Oficial do Município do Rio de Janeiro 1985 ; 30 jan.

23. Rio de Janeiro. Lei $\mathrm{n}^{\circ} 1353$, de 10 de novembro de 1988. Dispõe sobre a obrigatoriedade de desinsetização e desratização em creches etc. Diário Oficial do Município do Rio de Janeiro 1988; 16 nov.

24. Rio de Janeiro. Lei no 1662, de 23 de janeiro de 1991. Dispõe sobre a obrigatoriedade de frequência a curso de noções de higiene nas condições. Diário Oficial do Município do Rio de Janeiro 1991; 31 jan.

25. Rio de Janeiro. Lei no 3401, de 20 de maio de 2002. Altera a qualificação essencial da categoria funcional de Merendeira. Diário Oficial do Município do Rio de Janeiro 2002; 21 maio.

26. Rio de Janeiro. Lei $\mathrm{n}^{\circ} 3.527$, de 07 de abril de 2003. Monitoramento da água utilizada em estabelecimentos de ensino e saúde. Diário Oficial do Município do Rio de Janeiro 2003; 8 abr.

27. Brasil. Lei no 11.346 , de 15 de setembro de 2006 Cria o Sistema Nacional de Segurança Alimentar e Nutricional (SISAN) com vistas em assegurar o direito humano à alimentação adequada e dá outras providências. Diário Oficial da União 2006; 16 set.

28. Rio de Janeiro. Lei Ordinária nº 4.991, de 22 de janeiro de 2009. Dispõe sobre a obrigatoriedade da limpeza das caixas de gordura nas edificações do município do RJ. Diário Oficial do Município do Rio de Janeiro 2008; 23 jan.

29. Brasil. Lei $n^{\circ} 11.947$, de 16 de junho de 2009. Novas diretrizes do Programa de Alimentação Escolar. Diário Oficial da União 2009; 17 jun.

30. Prefeitura do Distrito Federa. Decreto ${ }^{\circ} 13.355$, de 13 de outubro de 1956. Subordina o setor de Alimentação do Escolar a Secretaria Geral de Educação e Cultura. Profissões afins ao Instituto: professores, médicos, nutricionistas, atendentes, assistente social, entre outros. Diário Oficial da União 1956; 15 out.

31. Prefeitura do Rio de Janeiro. Decreto $\mathrm{m}^{\circ} 6.235$, de 30 de outubro de 1986. Aprova o Regulamento da Defesa e Proteção da Saúde no tocante a alimentos e à Higiene Habitacional e Ambiental. Diário Oficial do Município do Rio de Janeiro 1986; 3 nov. 
32. Prefeitura do Rio de Janeiro. Decreto no 15.411, de 20 de dezembro 1996. Consolida a Organização Básica do Poder Executivo Municipal como as atribuições do Instituto de Nutrição Annes Dias. Diário Oficial do Município do Rio de Janeiro 1996; 23 dez.

33. Prefeitura do Rio de Janeiro. Decreto ${ }^{\circ} 21.217$, de 01 de abril de 2002. Proíbe, no âmbito das Unidades Escolares da rede municipal de ensino, adquirir, confeccionar, distribuir e consumir os produtos como balas, doces a base de goma, gomas de mascar etc. Diário Oficial do Município do Rio de Janeiro 2002; 2 abr.

34. Prefeitura do Rio de Janeiro. Decreto no 21.585, de 19 de junho de 2002. Procedimento a ser adotado nas vistorias em empresas interessadas no fornecimento de gêneros alimentícios no âmbito municipal. Diário Oficial do Município do Rio de Janeiro 2002; 20 jun.

35. Prefeitura do Rio de Janeiro. Decreto ${ }^{\circ} 25.673$, de 17 de agosto de 2005. Novos critérios para o Curso de Noções Básicas em Manipulação de Alimentos. Diário Oficial do Município do Rio de Janeiro 2008; 18 ago.

36. Prefeitura do Rio de Janeiro. Decreto no 26.286, de 24 de março de 2006. Altera a estrutura organizacional da Superintendência de Controle de Zoonoses, Vigilância e Fiscalização Sanitária as Secretaria Municipal de Saúde (Serviço de Vigilância Sanitária em Creches e Escolas). Diário Oficial do Município do Rio de Janeiro 2006; 18 abr.

37. Prefeitura do Rio de Janeiro. Decreto no 29.569, de 08 de julho de 2008. Estabelece procedimento a ser adotado nas vistorias em empresas interessadas no fornecimento de gêneros alimentícios no âmbito municipal. Diário Oficial do Município do Rio de Janeiro 2008; 8 jul.

38. Prefeitura do Rio de Janeiro. Decreto no 29.687, de 12 de agosto de 2008. Estabelece os critérios para o licenciamento de edificações destinadas às escolas e creches da rede pública municipal. Diário Oficial do Município do Rio de Janeiro 2008; 12 ago.

39. Prefeitura do Rio de Janeiro. Secretaria Municipal de Saúde do Rio de Janeiro. Resolução $n^{\circ} 752$, de 10 de janeiro de 2001. Dispõe sobre a limpeza e desinfecção de caixas d'águas e de cisternas. Diário Oficial do Município do Rio de Janeiro 2001; 11 jan.

40. Brasil. Ministério da Saúde (MS). Agência Nacional de Vigilância Sanitária (Anvisa). Resolução no 50, de 21 de fevereiro de 2002. Regulamento Técnico para planejamento, programação, elaboração e avaliação de projetos físicos de estabelecimentos assistenciais de saúde. Diário Oficial da União 2002; 22 fev.

41. Prefeitura do Rio de Janeiro. Resolução nº 604, de 11 de setembro de 2002. Regulamenta os veículos de transporte de alimentos destinados ao consumo humano, refrigerados ou não, em condições seguras. Diário Oficial do Município do Rio de Janeiro 2002; 12 set.

42. Prefeitura do Rio de Janeiro. Secretaria Municipal de Educação. Resolução no 008 , de 12 de dezembro de 2002. Institui o Programa de Qualidade de Água e Alimentos em Escolas e Creches. Diário Oficial do Município do Rio de Janeiro 2002; $13 \mathrm{dez}$.
43. Prefeitura do Rio de Janeiro. Secretaria Municipal de Educação. Resolução no 849, de 5 de novembro de 2004. Altera e revoga dispositivos da Resolução SME No 816, de 05 de janeiro de 2004, esta que normatiza o funcionamento das creches públicas do Sistema Municipal de ensino e dá outras providências. Diário Oficial do Município do Rio de Janeiro 2004; 6 nov.

44. Prefeitura do Rio de Janeiro. Secretaria Municipal de Saúde. Resolução no 1370, de 31 de julho de 2008. Fornecimento de gêneros alimentícios por firmas interessadas. Diário Oficial do Município do Rio de Janeiro 2008; 5 ago.

45. Brasil. Ministério da Saúde (MS). Portaria no 321, de 26 de maio de 1988. Aprova as normas e os padrões mínimos que disciplinam a construção, instalação e o funcionamento de creches. 1988; Diário Oficial da União 1988; 27 maio.

46. Brasil. Ministério da Saúde (MS). Portaria no 518 , de 25 de março 2004. Estabelece os procedimentos e responsabilidades relativos ao controle e vigilância da qualidade da água para o consumo humano e seu padrão de potabilidade, e dá outras providências. Diário Oficial da União 2004; 26 mar.

47. Brasil. Ministério da Saúde (MS). Ministério da Educação (MEC). Portaria ${ }^{\circ} 1010$, de 8 de maio de 2006. Institui as diretrizes para a Promoção da Alimentação Saudável nas Escolas da educação infantil, fundamental e nível médio das redes públicas e privadas, em âmbito nacional. Diário Oficial da União 2006; 9 maio.

48. Brasil. Portaria SVS/MS no 326 de 30 de julho de 1997. Dispõe sobre o Regulamento Técnico sobre as Condições Higiênico-Sanitárias e de Boas Práticas de Fabricação para Estabelecimentos Produtores/Industrializadores de Alimentos. Diário Oficial da União 1997; 01 ago.

49. Brasil. Resolução - RDC no 275 de 21 de outubro de 2002. Dispõe sobre o Regulamento Técnico de Procedimentos Operacionais Padronizados aplicados aos Estabelecimentos Produtores/Industrializadores de Alimentos e a Lista de Verificação das Boas Práticas de Fabricação em Estabelecimentos Produtores/Industrializadores de Alimentos. Diário Oficial da União 2002; 23 out.

50. Brasil. Resolução - RDC no 216 de 15 de setembro de 2004. Dispõe sobre o Regulamento Técnico de Boas Práticas para Serviços de Alimentação. Diário Oficial da União 2004; 16 set.

51. Brasil. Ministério da Saúde (MS). Secretaria de Vigilância em Saúde. Departamento de Vigilância Epidemiológica. Manual Integrado de Vigilância, Prevenção e Controle de Doenças Transmitidas por Alimentos; 2010 (Serie A. Normas e Manuais Técnicos). [página na Internet]. [acessado 23 jan 2012]; [cerca de 158p.]. Disponível em: http://portal.saude.gov.br

Artigo apresentado em 13/06/2012

Aprovado em 20/09/2012

Versão final apresentada em 07/10/2012 